\title{
Scaling Up Classroom Coaching for Impactful Technology Use
}

Results from Year 2 of the Dynamic Learning Project 


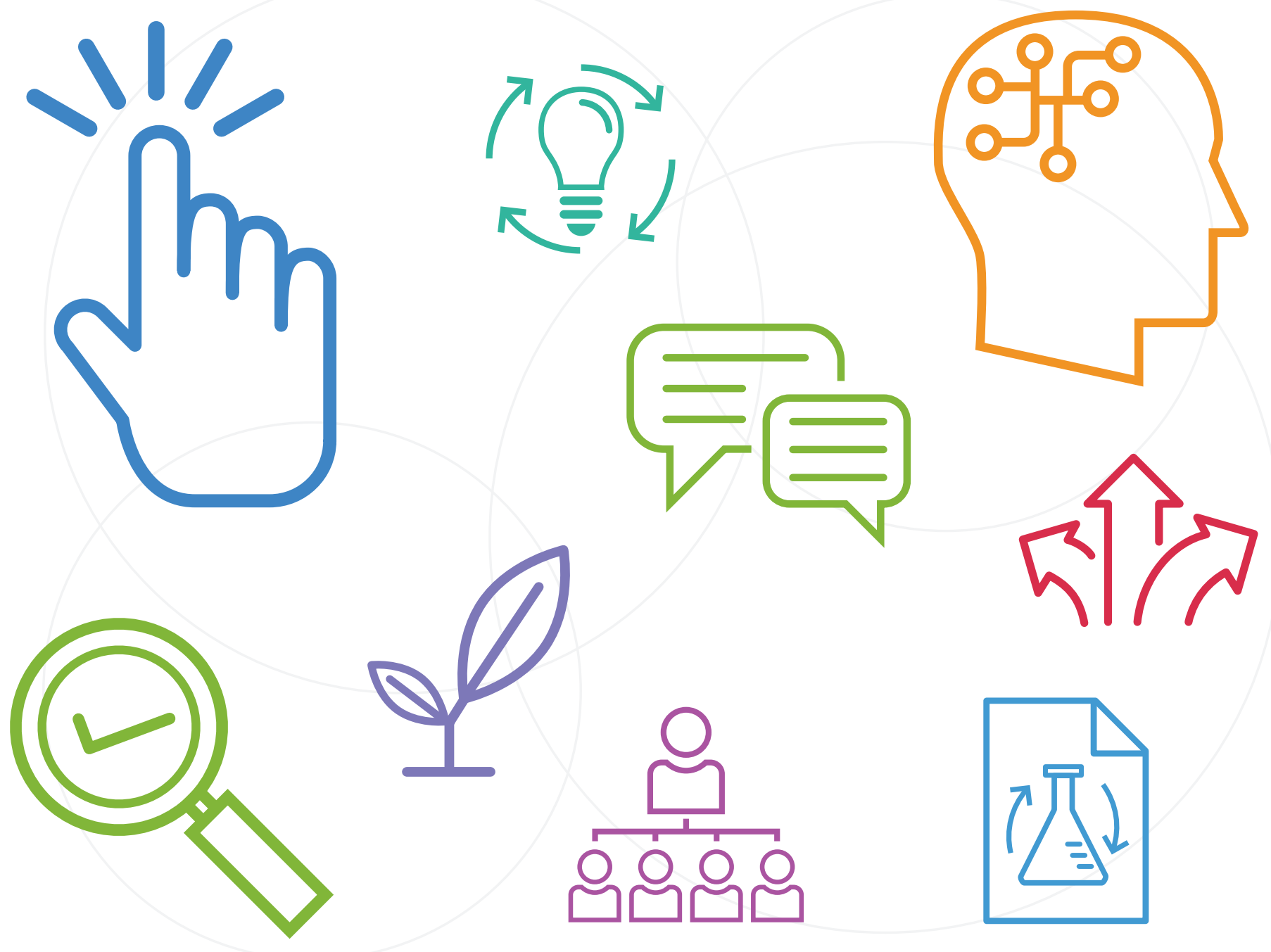

\section{Contents}

Executive Summary

4

Student Engagement and Learning

12

About the Dynamic Learning Project

5

Coach and Principal Growth

14

Part 1: Impacts of the Dynamic Learning

Part 2: Lessons for the Field: What Makes an

Project: What Do We Know After Two Years? ..... . 7

Effective Technology Coaching Program

Teacher Practice

8

Conclusion

23 
Executive Summary 


\section{Executive Summary}

The Dynamic Learning Project (DLP) is a classroom coaching program that helps schools leverage technology in impactful ways to support teacher professional growth and improve student engagement and learning. By embedding coaches within each participating school and providing ongoing professional development to coaches and school leaders as they implement the program, the DLP aims to drive sustained system-wide improvement.

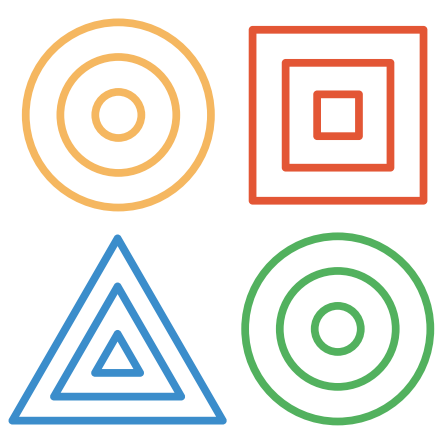

In the second year of the DLP, there is no longer a question of whether this classroom coaching program improves the impactful use of technology by teachers. With a strong and growing evidence base, we can increasingly turn our attention to how coaching improves teacher practices and student engagement and learning. Look at the numbers: more than $\mathbf{9 0}$ percent of participating teachers and principals indicated that DLP coaching can help them address their professional challenges and can improve their students' learning and engagement. One teacher said the DLP "has invigorated my teaching. It was like a breath of fresh air."

Teachers who received DLP coaching during the year reported greater skills in leveraging technology in their teaching compared to their peers who didn't receive DLP coaching. The DLP is unique in its collaborative approach and in how coaches are trained to support not just more technology use, but impactful technology use. Said another teacher: "I like the fact that we are focused on authentic learning with technology as the vehicle, not using technology just to use it."

But not only participating teachers benefit from the Dynamic Learning Project-school culture improves, and teachers who didn't participate in the program see the value as well. More than half of the teachers who did not receive coaching agreed or strongly agreed it was important to continue having DLP

coaching in their school and they would recommend the program to other teachers or schools.

DLP coaches take pride in working with teachers of various backgrounds, content expertise, and experience levels to provide personalized, thoughtful professional development. One coach shared that "almost every teacher in the building is using technology in a more meaningful way. In the past, devices were used for playing games or as babysitters when teachers needed to get something done. Now, teachers are using the devices as learning tools." Similarly, one district leader reflected on how the DLP can advance district-wide goals around use of technology: "The biggest hurdle to innovative technology implementation has often been teacher understanding [of] effective implementation and teachers' knowledge and comfort level with technology integration. The coaching provided through the DLP model has been instrumental in addressing the traditional hurdles and, therefore, creating a positive impact on technology integration."

"[The DLP] has invigorated my teaching. It was like a breath of fresh air."

- DLP Teacher

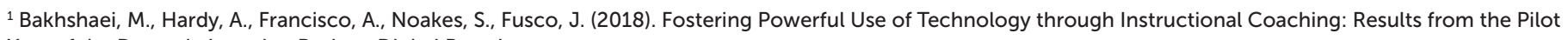
Year of the Dynamic Learning Project. Digital Promise. 
Year 1

2017-2018

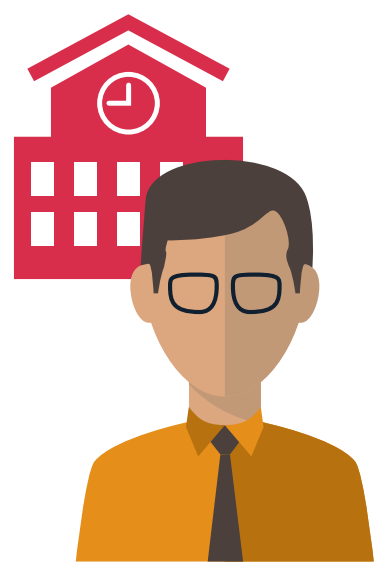

50 middle schools, 50 coaches
Year 2

2018-2019

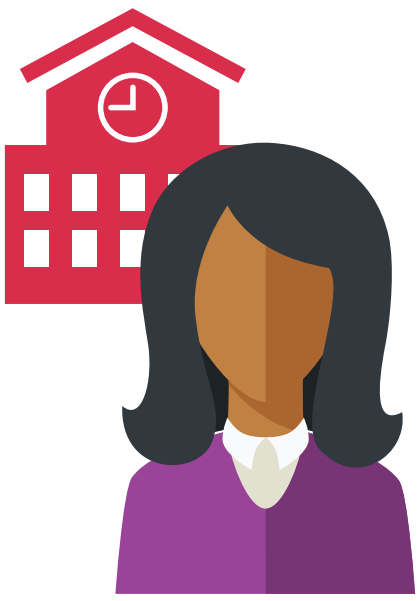

100 elementary, middle \& high schools, 100 coaches

\section{About the Dynamic Learning Project}

During its first year, the 2017-2018 school year, the DLP supported 50 schools in 20 districts across five states (Alabama, California, Pennsylvania, South Carolina, and Texas). Each district embedded a fulltime school-based technology coach in participating schools. In the second year (2018-2019), the program expanded to include additional districts in North Carolina and New York. The geographic classification of member schools varied widely, with some located in small-town rural settings and others located in large urban areas. A key driver for the program is a belief that schools can use coaching as a professional development technique to help bridge the second digital divide and develop impactful use of technology for all students.

Overall 1,945 teachers ( 43 percent of the teacher population in participating schools) participated in DLP coaching in year two. These teachers had varying levels of teaching experience. More than three quarters had at least five years of experience, a third had more than 15 years, and 23 percent had less than five years. The most commonly taught subjects were core academic subjects (science, math, English, and social studies).

Throughout the year, coaches typically worked with an average of nine teachers for eight-week coaching cycles. During these cycles, teachers would meet with coaches one-on-one and agree to work through the five steps in the DLP coaching model: (1) identifying a classroom challenge(s);

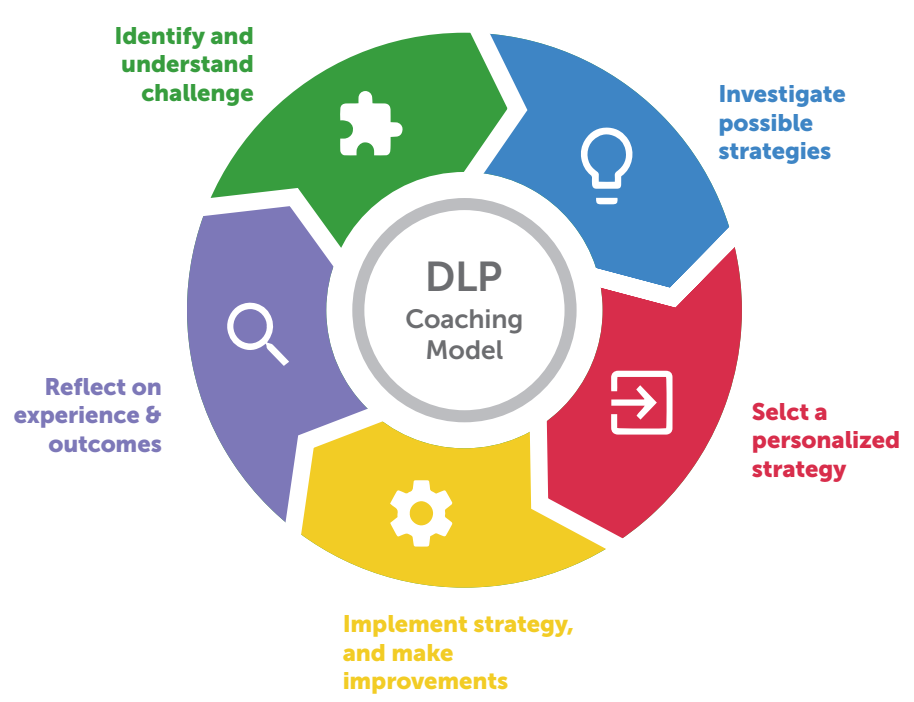
(2) brainstorming possible strategies; (3) selecting personalized strategies and tools; (4) implementing the selected strategies in the classroom through co-teaching, modeling, and/or observation of teaching practice; and (5) reflecting on the strategies. The program also provided coaches and principals in all 


\section{DLP Schools in Year 2}

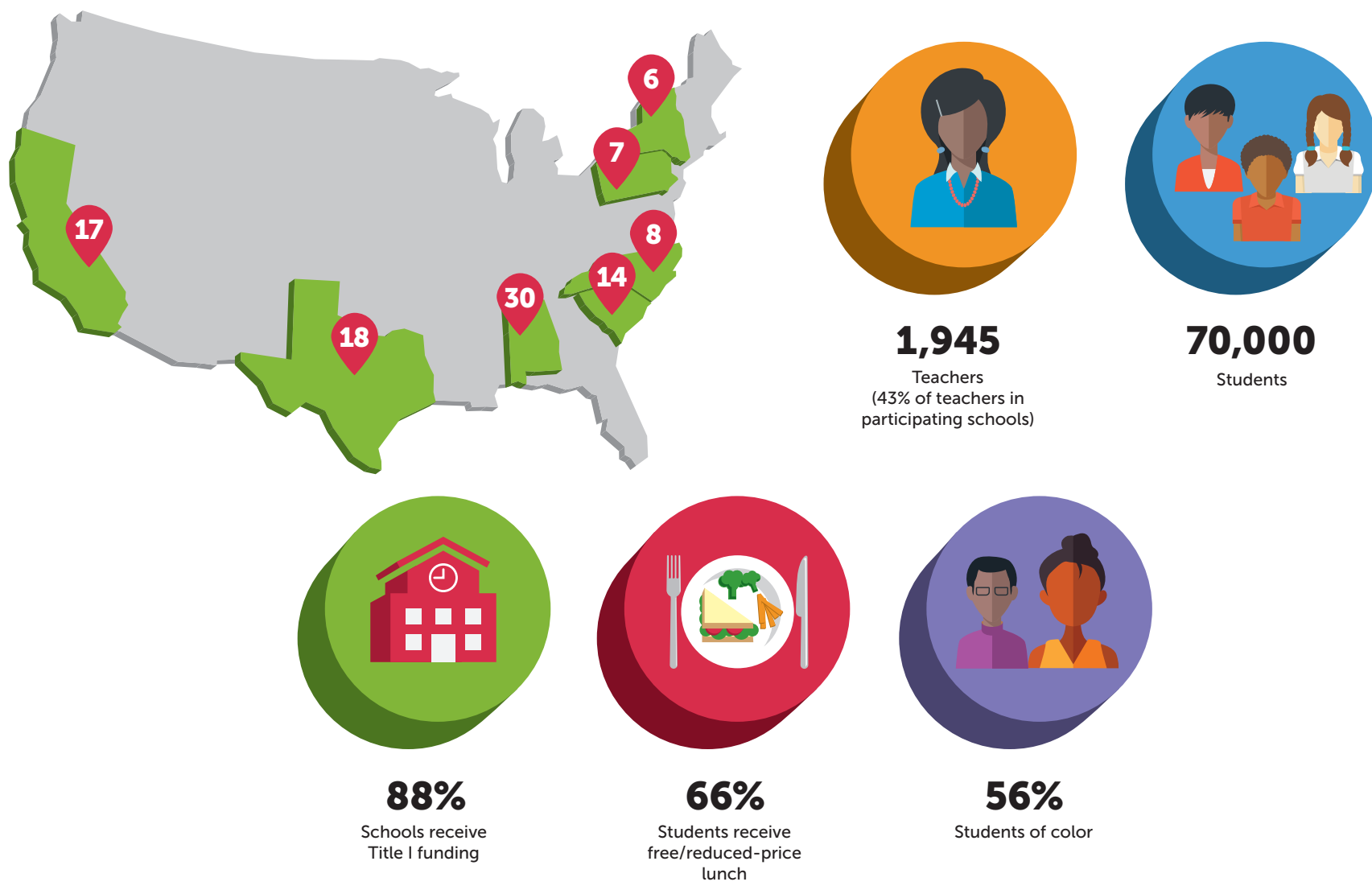

participating schools with sustained mentorship and ongoing professional development (PD), including participation in both regional and DLP-wide professional learning networks and in-person events ${ }^{2}$. Mentors served as accessible experts who could provide an outside perspective and personalized support to coaches, as well as to the principal at each school.

Our research on the impact of the DLP is multi-faceted, ranging from surveys to case study interviews and classroom visits in four schools that varied by

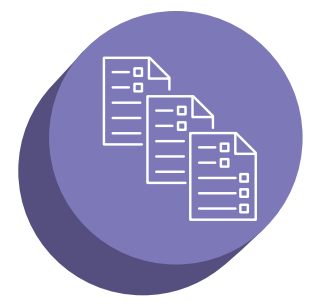

In-depth surveys 2x per year

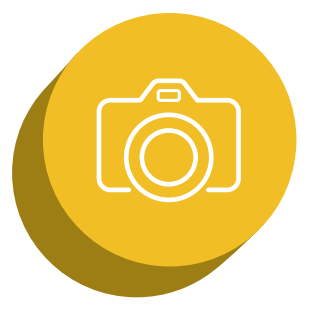

Snapshot surveys Monthly

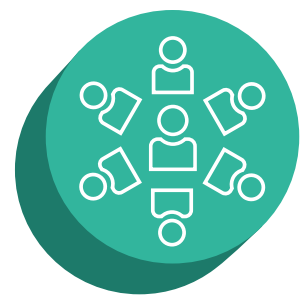

Interviews \& focus groups $2 x$ per year at each case study school

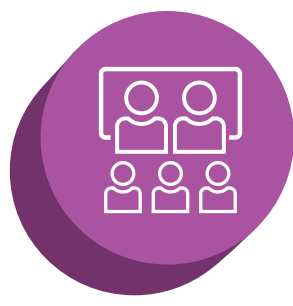

Classroom visits 2x per year at each case study school

\footnotetext{
${ }^{2}$ See lbid. for more information on support and resources that the DLP program provided to coaches and principals.

${ }^{3}$ All quantitative findings presented in this report are statistically significant at $\mathrm{p}<.05$ or better, with the exception of principal data, where the small sample size resulted in notable but not statistically meaningful results.
} 


\section{Part 1}

Impacts of the Dynamic Learning Project: What Do We Know After Two Years? 
More DLP teachers reported increased technology use this year compared to last.

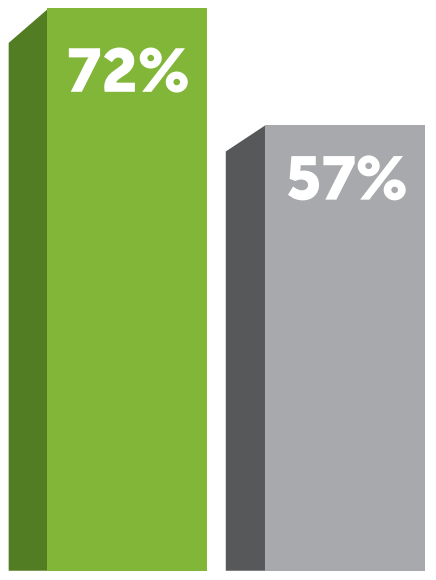

Hours per week teachers used technology in their teaching practice

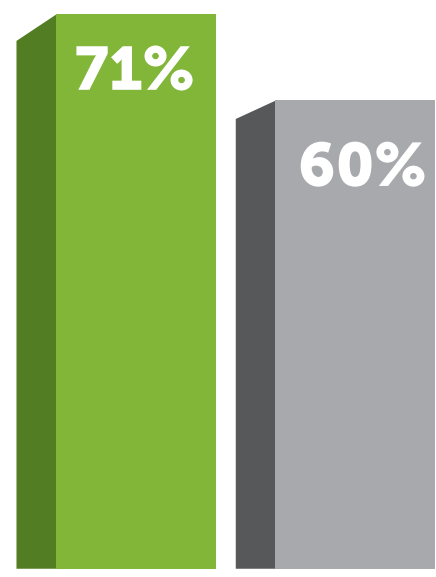

Days overall students used technology for class assignments

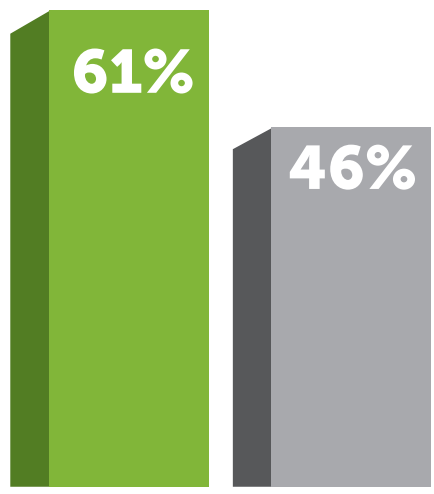

\section{Courses/subjects teachers taught using technology in their teaching practice}

\section{Teacher Practice}

Our research showed that participating in DLP coaching is first of all associated with a significant increase in the frequency of teacher and student use of technology. More than 70 percent of DLP teachers reported using technology more hours and days each week than they had the previous year (compared to 57 percent and 60 percent, respectively, for non-DLP teachers). Moreover, 61 percent of DLP teachers reported increasing use of technology in more courses/subjects than last year, compared to 46 percent of non-DLP teachers.

As part of the Dynamic Learning Project, we looked at not just whether coaching would help teachers

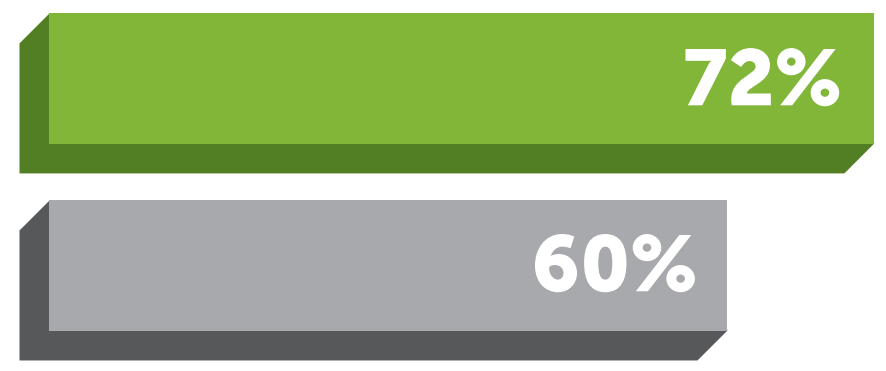

More DLP teachers reported having a strong or very strong ability to select and use technology to improve their teaching approaches (pedagogy). use technology more frequently, but whether coaching would help teachers use technology in more meaningful ways with their students. To that end, we focused on "Impactful Technology Use," which refers to educators' ability to use technology in their teaching. Compared to non-DLP teachers, by the end of the year, more DLP teachers (72 percent versus 60 percent) reported having a strong or very strong ability to select and use technology to improve their teaching approaches (pedagogy). Not only that, DLP teachers also more frequently reported being better able to select and use technology to teach their specific content area (74 percent versus 62 percent).

We define "Impactful Technology Use" as the ability of educators to develop their students' skills in six

\section{$74 \%$}

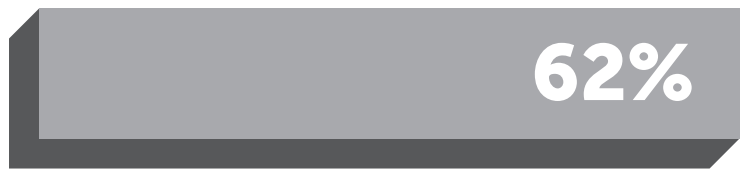

More DLP teachers reported being better able to select and use technology to teach their specific content area. 


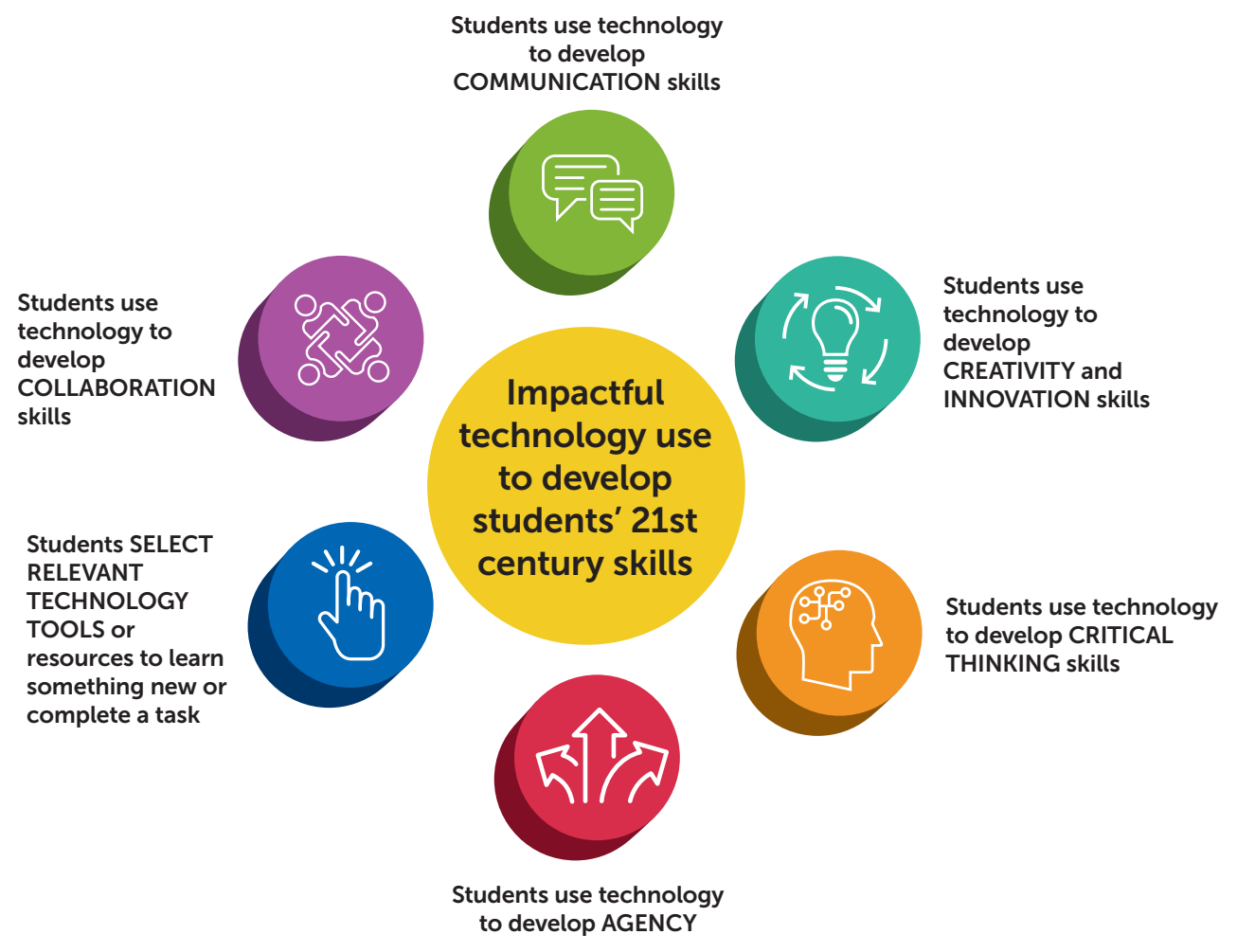

categories: agency, collaboration, communication, creativity, critical thinking, and ability to select relevant technology tools.

Teachers who received DLP coaching reported feeling more confident in their ability to use technology to engage students in developing those skills across all six indicators. For example, 80 percent of DLP teachers agreed that they "can create opportunities for students to use technology to work together to solve problems, complete tasks, and accomplish common goals," compared to 67 percent of non-DLP teachers.

The DLP is a challenge-based coaching model where the coach and teacher collaborate to address a teacher-selected challenge. More than 90 percent of participating teachers reported at least some improvement in the following teaching challenges as a result of working with a DLP coach: assessment, differentiation, instructional strategies to support a specific content area, classroom management,

More DLP teachers agreed that they are able to use technology in impactful ways that develop students' 21st century skills.

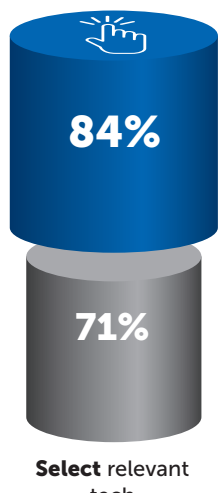

tech

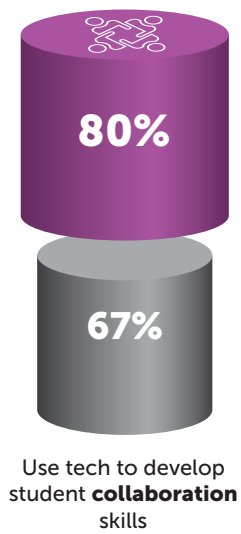

skills

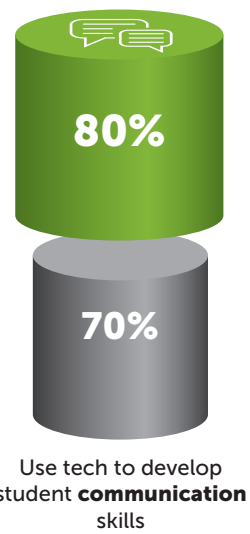

DLP Teachers

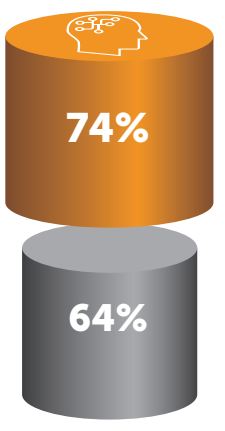

Use tech to develop student Use tech to develop skills
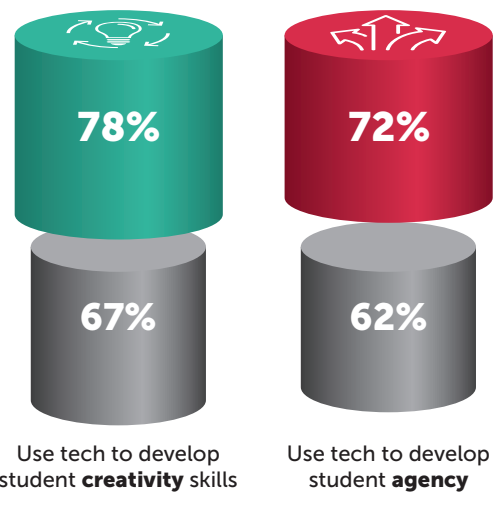

Use tech to develop student agency

Non-DLP Teachers 
Nearly all DLP teachers improved in each of the key challenge areas.

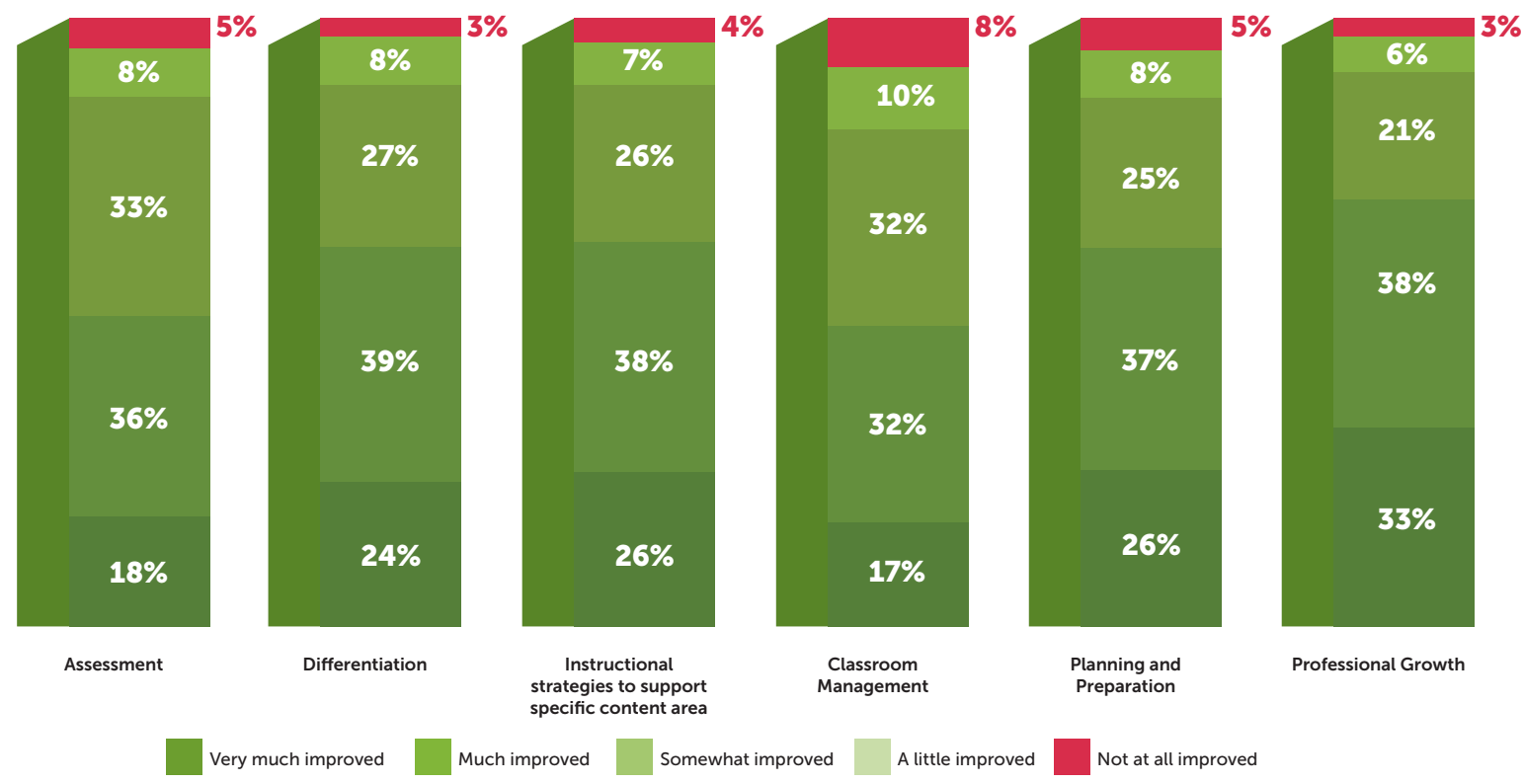

planning and preparation, and professional growth. Remarkably, in all six of these categories, more than half of participating teachers reported "much" or "very much" improvement. Importantly, by addressing one challenge category, teachers often make progress in other categories, as well. One sixth grade math and science teacher shared how she is now using technology to collect more frequent and actionable formative assessment data in her classroom, which in turn informs how she differentiates instruction: "I am [now] able to quickly assess where kids are and then... figure out strategies to support their learning."

In the DLP, teachers drive every step of the process with the coach as partner. It is the teacher that sets the direction of the collaboration and has the ultimate choice in which challenges are addressed. This teacher-centric approach empowers the teacher to change their teaching practice and also creates changes such as teacher-reported increased autonomy and decreased job stress. At the end of the year, 65 percent of DLP teachers believed that teachers in their school have autonomy to make decisions about their instruction, compared to just 54 percent of their non-DLP colleagues. Moreover, 78 percent of teachers agreed that as a result of DLP coaching, they feel less stressed about their classroom challenges.

In interviews at the four case study sites, teachers explained that their collaboration with their coach helped to alleviate job stress, largely because they had someone by their side to help them manage the tasks of planning and preparing lessons. Teachers reported being more confident in their ability to adapt lessons even when things don't initially go according to plan. When the workload temporarily increased because the teacher was creating something original, learning

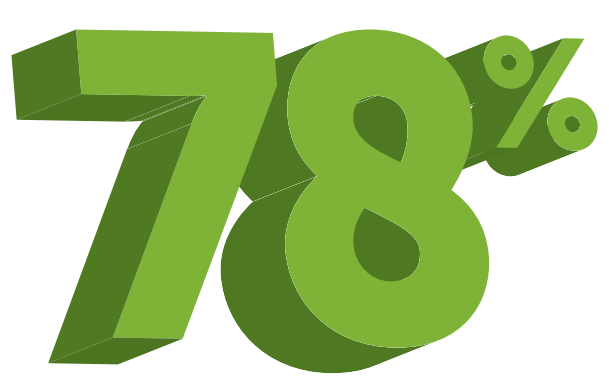

Teachers agreed that they feel less stressed about their classroom challenges as a result of DLP coaching. a new skill, or experimenting with a new strategy, the perceived benefits could increase the teacher's overall job satisfaction. One principal shared, "I think when [teachers] feel like they have the support that they need to do their jobs well in the classroom, then that helps with teacher retention because it improves job satisfaction."

The Dynamic Learning Project is not the only coaching model in existence. In addition to comparing DLP and nonDLP teachers, we also compared DLP participants with teachers who participated in other coaching programs. Teachers who participated in the DLP reported more meaningful coaching and professional 
development experiences. DLP teachers reported more frequent classroom observation sessions by the coach, more co-teaching, and more in-depth conversations about teaching scenarios than their colleagues receiving other coaching. The differences between the DLP and other programs is notably large when asked how often a classroom coach modeled an activity in their classroom-61 percent of DLP teachers said this occurred at least a few times a year, compared with 42 percent of participants in other coaching programs.

At the same time, it's important that we learn from the strengths of other programs. For instance, DLP participants did not have as many opportunities to observe other teachers and provide feedback as did participants in other coaching programs. The DLP may want to provide more opportunities to do this in the future and clarify the role of classroom visits as opportunities not only for coach observation but for teacher observation, as well.
One focus for DLP teachers is on their own professional growth as they learn alongside their students. Teachers and students can both become more confident addressing challenges. As one fourth grade teacher explained, "[Using new technology tools] was uncomfortable for me at first; having to teach kids how to do it when I've never really done it before is an uncomfortable thing. The kids need to see that journey, because that's what they're going to do when they're working on projects. They're going to fail, and they're going to need to change things and adapt and reflect and evaluate."

Teachers are encouraged even more as they see new ways of using technology to improve engagement and learning for their students. Said one high school math teacher: "Giving students the opportunity for choices in selecting their own technology tools and using them creatively has helped a lot. Their grades and engagement have gone up. The quality of their work has gone up."

\section{Teachers who received DLP coaching reported more frequent meaningful PD and coaching opportunities than teachers who participated in other coaching programs.}

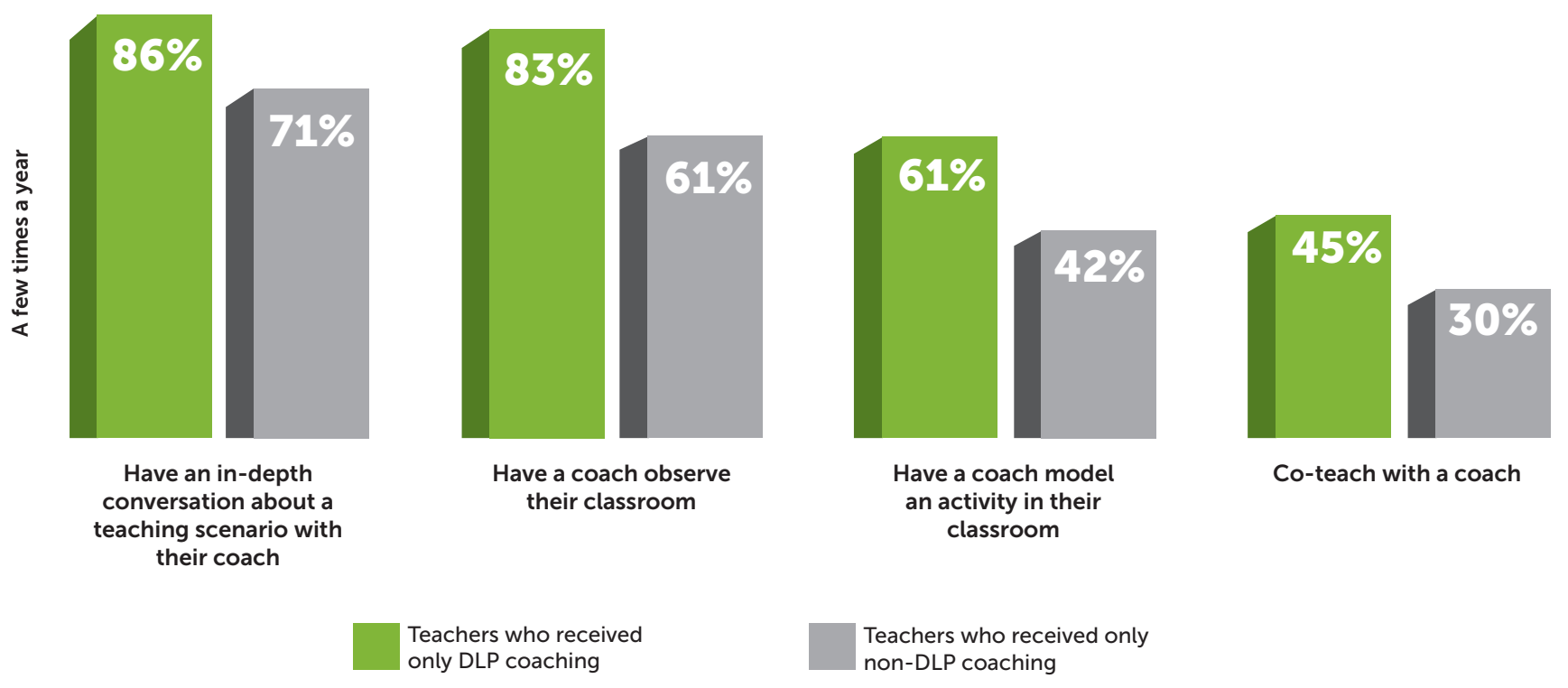



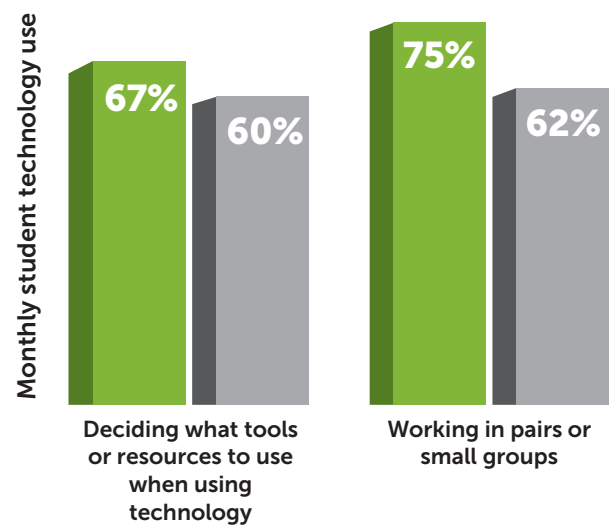

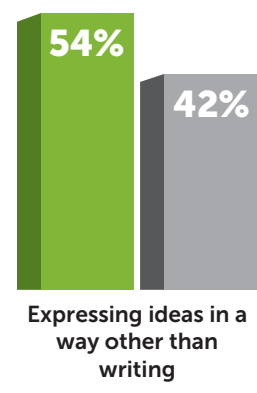

DLP Teachers

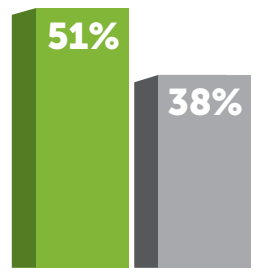

Creating something unique for the class

Non-DLP Teachers

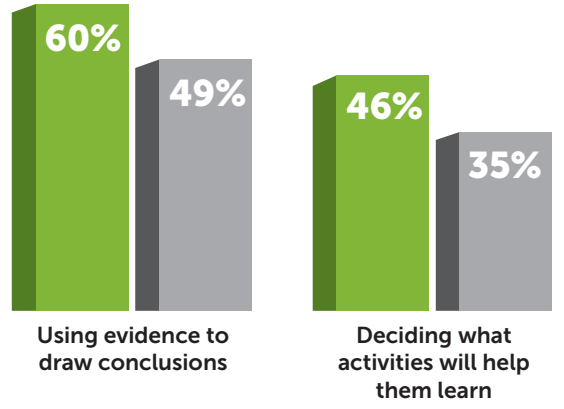

\section{Student Engagement and Learning}

By improving teacher practice, DLP coaching also leads to an increase in student engagement and learning.

Compared to teachers who didn't receive DLP coaching, DLP teachers felt more confident that they could impact their students' engagement and learning through impactful technology use. This confidence was reflected in their more frequent use of various practices. For example, compared to non-DLP teachers, DLP teachers recounted higher rates of technology used to have students collaborate in small groups ( 75 percent versus 62 percent), create unique products (51 percent versus 38 percent), and decide what activities will help them learn (46 percent versus 35 percent). For each of the skill areas, there were several similar examples.

Finally, compared to non-DLP teachers, more DLP teachers reported that their student technology use and skill development is having a positive impact on student engagement and learning. For example, 64 percent of DLP teachers, compared to 54 percent of others, reported a moderate or large positive impact (instead of just a little impact or negative impact) on student engagement and learning as a result of having students select relevant technologies.

\section{DLP teachers see more positive impact on student engagement and learning from using technologies to develop these 21st century skills.}

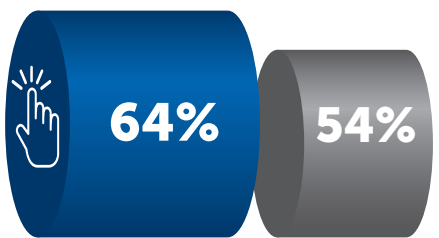

Select relevant tech

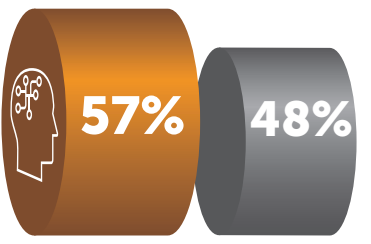

Use tech to develop student critical thinking skills

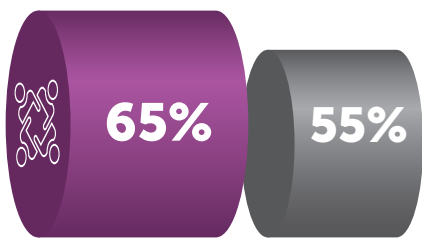
Use tech to develop student
collaboration skills

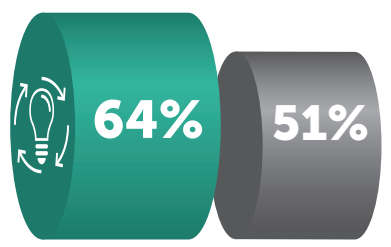

Use tech to develop student creativity skills

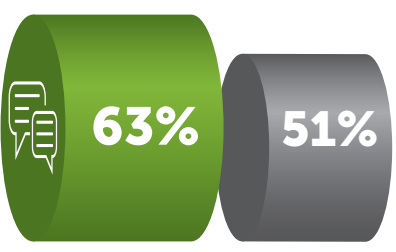

Use tech to develop student communication skills

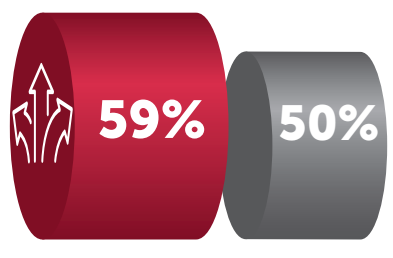

Use tech to develop student agency 
Teachers shared how their student engagement has improved. One high school math teacher stated, "[Student engagement] has gone up a lot, and I know a big part of that is how l've been changing my own approach." Another third grade teacher noted how things had changed for her students: "At the end of the day, it was challenging no matter what I was teaching; ... [students were just] done. And now they're like, 'Are we doing social studies?' And they're begging for it."

All case study principals also observed tangible changes in both student learning and engagement. One principal explained that the changes they saw were palpable: "You go into classrooms, they feel like more comfortable, joyful spaces. Colleagues are generally reporting improved achievement in most areas, [and] generally, all of our data across the board has improved this year. You can't not attribute it to what [the] DLP brought."

In focus groups at case study sites, students agreed that they were engaged when learning opportunities gave them choice and voice, as well as chances to collaborate and be creative. They reported enjoying using technology to transform abstract ideas into tangible products, and to search for information to help fill gaps in their understanding. Students unanimously reported that using technology in this way helps them understand the
"You go into classrooms, they feel like more comfortable, joyful spaces. Colleagues are generally reporting improved achievement in most areas, [and] generally, all of our data across the board has improved this year. You can't not attribute it to what [the] DLP brought.

\section{- DLP Principal}

her and "speed up the learning process." Rather than passively waiting for information from the teacher, she takes ownership of searching for supplemental information on her own because she wants to expand her learning beyond the scope of the lesson.

As we spoke with students throughout the year, we heard many examples of ways that technology helped them learn more effectively by augmenting their comprehension or depth of understanding.

In the second year of the DLP, we found that in addition to improved engagement and learning, students demonstrated more agency in how and when they use technology. Students were able to offer important perspectives on their own perceptions and use of technology. Most students explained that whether they prefer to use technology in a lesson or not depends on the specific context of the lesson or activity. Importantly, students do not want their teachers to use technology to completely replace their own delivery of content and directions, but they do want to use technology when it adds to their engagement and learning. Sustained, thoughtful support from DLP coaches can help teachers use technology to enhance engagement and learning and avoid its use as a distraction or replacement for the teacher.

The most important remaining question for the Dynamic Learning Project is content better and pursue additional knowledge on topics that interest them. For instance, one student who described herself as "very curious" explained that she constantly uses technology at school to research topics that interest about its impact on student achievement. We have reasons to believe the DLP leads to improved student achievement because DLP teachers report stronger estimates of student engagement and learning. 
The DLP was designed based on research-proven strategies to incorporate prior knowledge and lesson review into professional development. Hattie (2015) ${ }^{5}$ saw positive effects for these PD characteristics and many of the student learning strategies the DLP supports. Taken together, research suggests that these improvements in student engagement should lead to increased achievement, and the Dynamic Learning Project is currently collecting data with partner districts to see if we can address this question in late 2019.

\section{Coach and Principal Growth}

One of the unique qualities of the Dynamic Learning Project is that it is not only teachers and their students who benefit. The program provided coaches and principals in all participating schools with sustained mentoring, ongoing professional development and opportunities to participate

\section{Coaches increasingly felt confident about their coaching skills.}

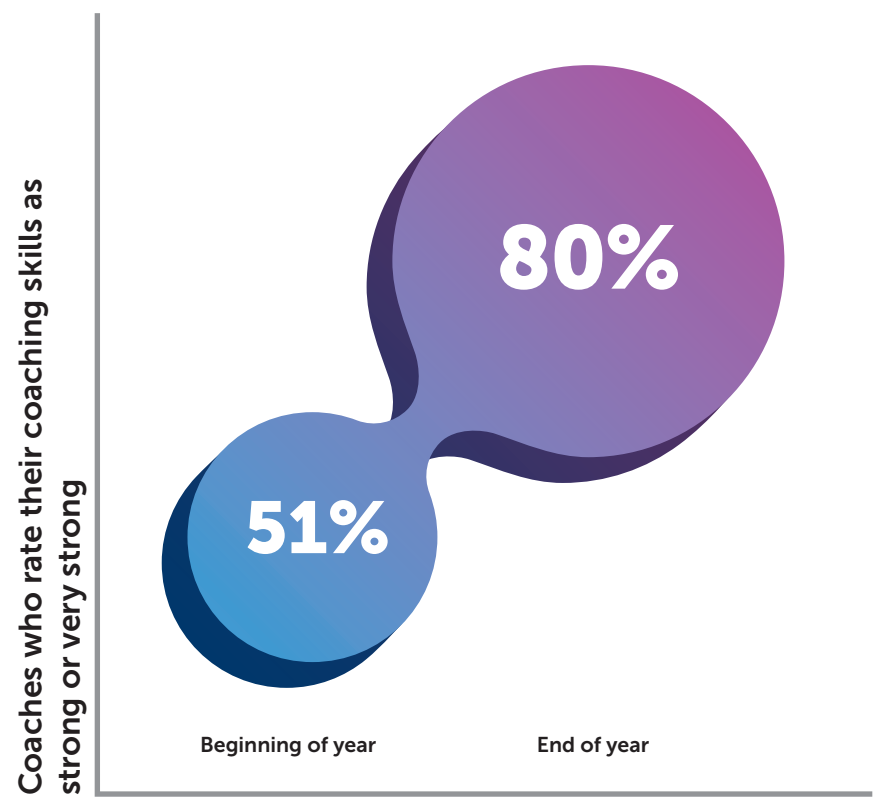

in regional and DLP-wide professional learning networks (PLNs). As a result of these multiple growth opportunities, 80 percent of coaches stated that their coaching skills were strong at the end of the year, up from just 51 percent at the start of the year. A striking 92 percent of participating teachers agreed with this, believing that their coaches have the knowledge and skills they need to integrate technology in their teaching.

The multiple growth opportunities that the DLP program provides for coaches and principals also resulted in principals having more confidence in their skills in leading coaching programs. By the end of the year, almost 85 percent of principals rated their leadership skills in coaching programs as strong or very strong, almost a third more than did so at the start of the year (65 percent). Principals do not merely lend support and leadership to the DLP; they benefit from the program as well.

\section{Principals increasingly felt confident about their leadership skills.}

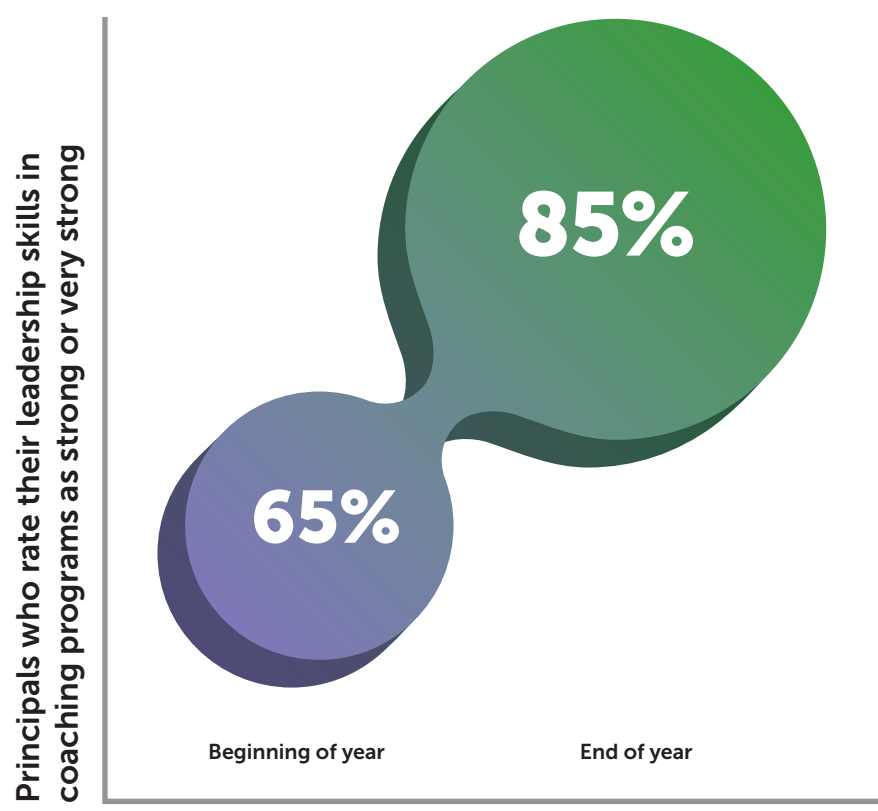




\section{Part 2}

\section{Lessons For the Field: What Makes an Effective Technology Coaching Program}



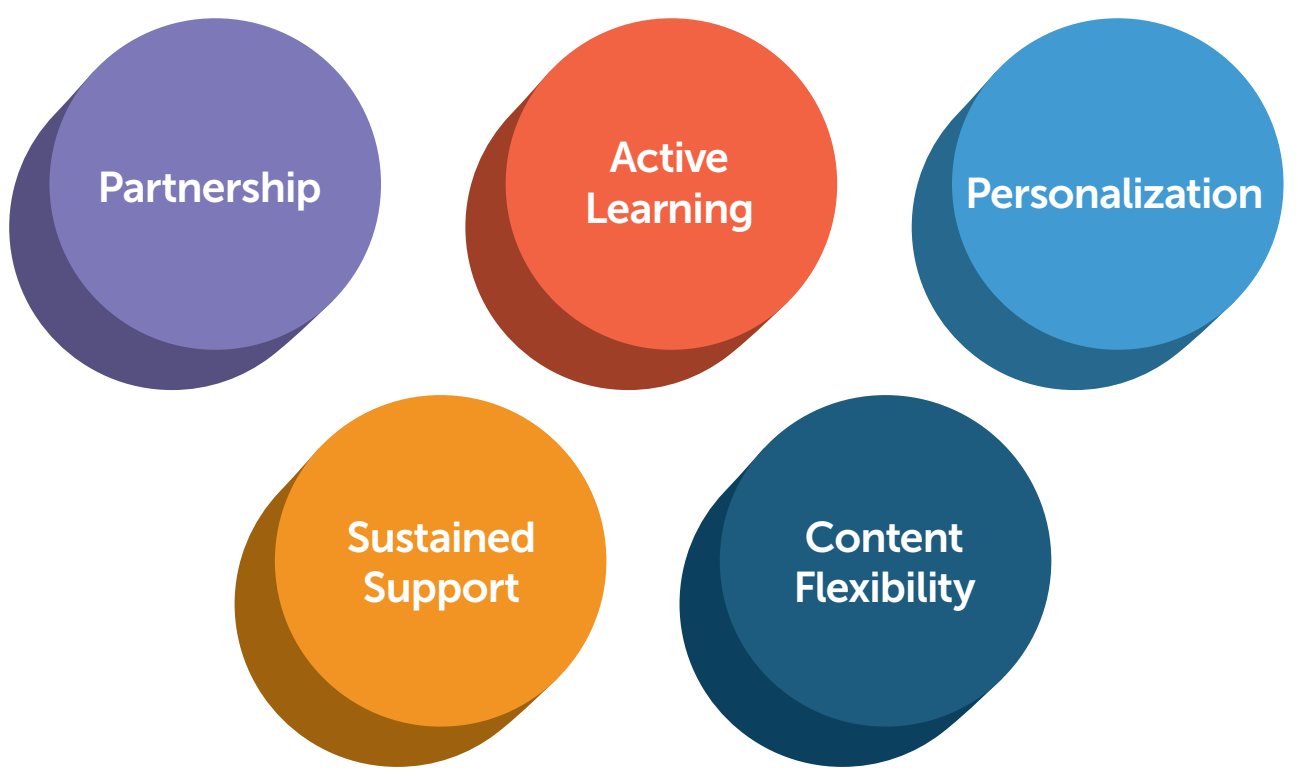

As the program doubled in size in year two, we continued to see strong, positive impacts across sites as a result of having embedded DLP coaches. Building on findings from year one, we identified five aspects of the Dynamic Learning Project that we think account for much of this exciting success:

\section{Partnership}

We found that when defined, understood, and implemented as a school-based partnership among administrators, coaches, and teachers, classroom coaching programs like the DLP are more likely to be successful in creating change in teacher practice. One hundred percent of DLP coaches and principals agreed that coaching is a partnership with shared responsibilities. They were also successful in transferring this mindset to their teachers. At the end of year two, more than 82 percent of teachers who received DLP coaching reported that their principal and coach provided an environment where they felt empowered to be a collaborator in the coaching program. Teachers who described coaching as a partnership reported greater improvement in addressing a range of classroom challenges.

\section{A coaching partnership should be voluntary and non-evaluative for teachers.}

Part of what defines the DLP is that teachers voluntarily enter into this partnership with their coach. Over the two years of the DLP, nearly all (94 percent)
DLP teachers said they participated in the program willingly. When teachers volunteered for coaching, they reported greater improvement in addressing their classroom challenges because they were more likely to take ownership of the process.

Another key component of the partnership is that teachers trust that information shared with the coach will remain confidential and they don't need to be afraid of failing as they experiment with new strategies and technology tools. Teachers reported being more willing to volunteer to participate when they feel that coaching is non-evaluative. One principal explained that "the reason people engage [in coaching] willingly is because of the confidentiality connected to it." Nearly all (95 percent) DLP teachers agreed that their coach communicated with them in a non-evaluative way. Teachers who reported non-evaluative coaching were more likely to report progress in using technology, and more likely to see improvement in their teaching practice as a result of working with their coach.

\section{Coaches and teachers are co-owners.}

By collaborating in regular meetings and classroom visits, DLP coaches and teachers co-constructed lessons, designing and implementing materials that fit the needs of each specific classroom context. This collaboration also afforded teachers contextualized opportunities for self-reflection. Working with the DLP coach helped teachers-even those who were 
initially fearful about using technology-take risks and strengthen their own processes for learning and innovation.

While teachers and coaches co-constructed lessons, the direction was driven by the teacher. "She's not telling [me] what to do; she's just helping me with what I want to do," said one high school math teacher. Another high school math teacher explained that, "A good coach is somebody who's there to give you guidance while also giving you autonomy."

As the relationship between teacher and coach strengthened throughout the year, teachers became increasingly comfortable taking the lead in initiating ideas and determining next steps. One fifth grade teacher explained, "At first when we started collaborating, [the coach] would come in the classroom and help me implement strategies and technology tools. I was very unsure of what I was doing. Now, I'm coming up with ideas and implementing them more on my own."

Additionally, as teachers take more ownership of their learning, they also communicate their new skills to other teachers. In this way, the DLP catalyzes partnerships to shift school culture to be more innovative and collaborative. Principals reported that substantially more teachers were sharing ideas and teaching practices by the end of the year ( 62 percent) compared to the beginning of the year ( 46 percent).

\section{Principals nurture the partnership.}

The importance of the principal role in coaching programs cannot be overstated. Principals are in a unique position to provide administrative and leadership support for coaches working with teachers in their schools. More than half of the coaches said that the primary responsibility of principals is to communicate with staff about the program, demonstrate their support and belief in coaching, build buy-in, and set expectations. When principals remain involved throughout the year in the implementation of the coaching program in their school, teachers feel less stressed about their classroom challenges, feel better about their coaches' coaching skills, and show more improvement in their teaching practices. As one principal said, "The principal needs to be the biggest cheerleader for the program and support teachers when they are unsure of themselves and the risks that they will be taking."

As leaders, principals should also empower their

\section{Mentors in the DLP Model}

\section{"The most vital resource of the entire program" - DLP Coach}

One component of the program is ongoing support provided to coaches and administrators by mentors. This expert assistance emerged as one of the defining qualities of the DLP. The majority of coaches ( 87 percent) and principals ( 90 percent) agreed or strongly agreed that the mentor's role is essential for implementing an effective classroom coaching program. Coaches described the mentor as an accessible guide who can share expertise, objective feedback, and encouragement, and serve as a thought partner. Mentors provide personalized support in solving issues that arise over the course of the year for DLP coaches.

\section{The MENTOR role is essential}

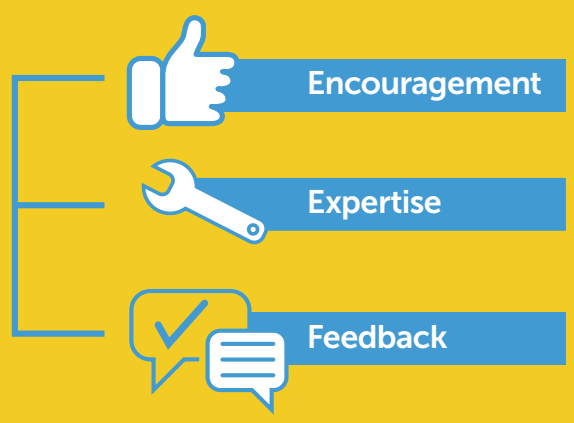

"Having a mentor is like having a life line. She is there

to guide me, to listen, to make suggestions. She

supports me and celebrates the successes along the

way. Everyone needs a coach, but every coach needs a

mentor."

-DLP Coach 
coaches by giving them freedom to build the program based on the context of their school. When the principal allows the coach autonomy to make decisions, it enhances trust and respect in the coach-principal relationship, strengthening that partnership. On the other side, when coaches feel more autonomy, they can more easily build and develop the necessary rapport with teachers and personalize the type of support that they provide to a greater degree. The principal-coach relationship deepens over the course of the year as the coach and principal consistently collaborate in regular meetings. In schools where the coach and principal met frequently, they appeared more aligned in their efforts to foster a culture of innovation and collaboration, and the principal felt better equipped to celebrate DLP-related successes and generate teacher buy-in.

The positive changes we are seeing in DLP schools are a result of the partnership between the principal, coach, and teacher. The program is attuned to how all parties are collaborating, thinking, and growing in the DLP. "This is a true partnership with each member playing an important role, and it all begins with building strong relationships and continuously nurturing trust," shared one principal.

\section{Active Learning}

The DLP provides opportunities for teachers to engage in active learning that is relevant and directly applicable to their classroom and students. By "active learning," we mean the support provided by the coach is connected to each individual teacher's classroom challenges in a way that is structured around learning by doing. Specifically, all teachers in the model analyze and select strategies associated with their specific challenge, try them in the classroom, and then reflect on their effectiveness in addressing their classroom challenge. The DLP model encourages frequent and different types of meetings with coaches to discuss and review teacher practices as well as student work.

During these coaching opportunities, teachers consistently engage in "sense-making" activities as they directly apply the practices they are learning to their classrooms. Teachers feel coaches help them actually apply new strategies and ideas into their practice in a way that goes beyond what traditional professional development activities could provide them. One eighth grade English/language arts teacher explained that she has "been able with [the coach] to get down to the nitty gritty, the little tiny details that you usually don't have time for in regular PD. With lots of other PDs, I'm not able to use what I've learned. ... With [my coach] it was immediate application, which was wonderful."

A district lead explained the successful collaborative approach in this way: "It has to be in the classroom, in the real work, not a set-aside. It doesn't work if the idea is, 'I'm going to just tell you what to do and then

\section{More than 97 percent DLP teachers reported these coaching opportunities helped them address their classroom challenges:}

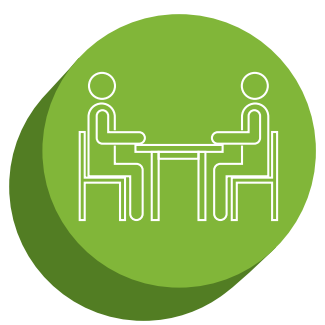

1:1 formal meetings with their coach

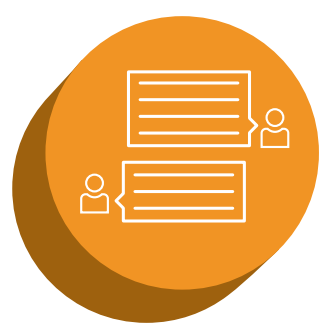

Informal conversations with their coach

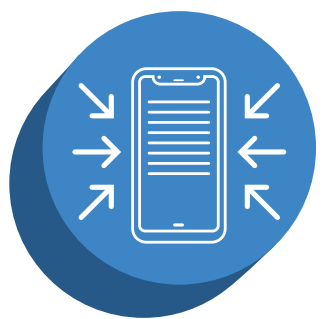

Coach classroom visits for data collection

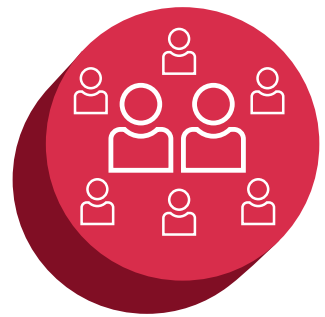

Coach classroom visits for co-teaching/ modeling

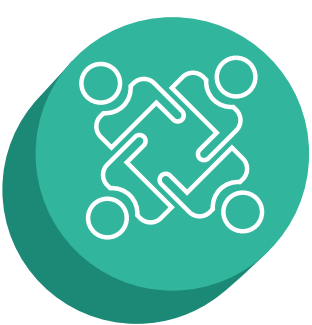

Coach-facilitated group professional development 
hope that you figure it out when you get in there with real kids.'"

\section{Personalization}

Another strength of the DLP is the large degree of personalization available to teachers compared to traditional professional development experiences. Eighty-five percent of DLP teachers reported that their professional development was a good fit with what they needed or wanted in their current teaching assignments, compared with 70 percent of non-DLP teachers. More DLP teachers also reported that their professional development recognized and built on their previous knowledge and experience ( 89 percent versus 80 percent of non-DLP teachers).

One third grade teacher shared that through classroom visits, the coach is able to "be in my shoes and see the problems that come up." Consequently, the coach is able to make targeted suggestions and discuss what would work best for the students in that teacher's classroom. One coach pointed out that "resources, curriculum, and time are very different for different subject area[s]. Often, what works for one subject will not work for another. Each subject and each teacher presents a new and different challenge." A sixth grade science teacher explained, "We all need different things and we all struggle with different things, so I think it's great that it works on what I need personally in my setting."
In addition to personalizing for the teacher, DLP coaching is also about adapting the program to meet the needs and culture of specific schools and districts. In case study schools, most principals said the DLP is most effective when it is aligned with district and school goals in a way that is organic and, crucially, doesn't supercede teacher ability to select their own challenges that they want to tackle.

\section{Sustained Support}

As opposed to isolated or episodic PD, sustained support with a coach is intricately linked to and enables personalization. Sustained support, delivered over a series of weeks and months, allows for relationship building, which yields increased comfort between the coach and the teacher. This comfort level that arises from sustained collaboration goes hand in hand with the non-evaluative nature of DLP coaching. It also provides the coach with more knowledge to tailor their support and create opportunities for a more sustainable change in teaching. Teachers who reported more hours of coaching were more likely to see improvement in addressing each of their teaching challenges and in their professional growth overall.

Teachers benefit from sustained support and have more time to experiment, reflect, and iterate. Unlike a lot of professional development that is composed of "one-off" events, 85 percent of DLP teachers reported that their professional development included enough time during and between events to think carefully
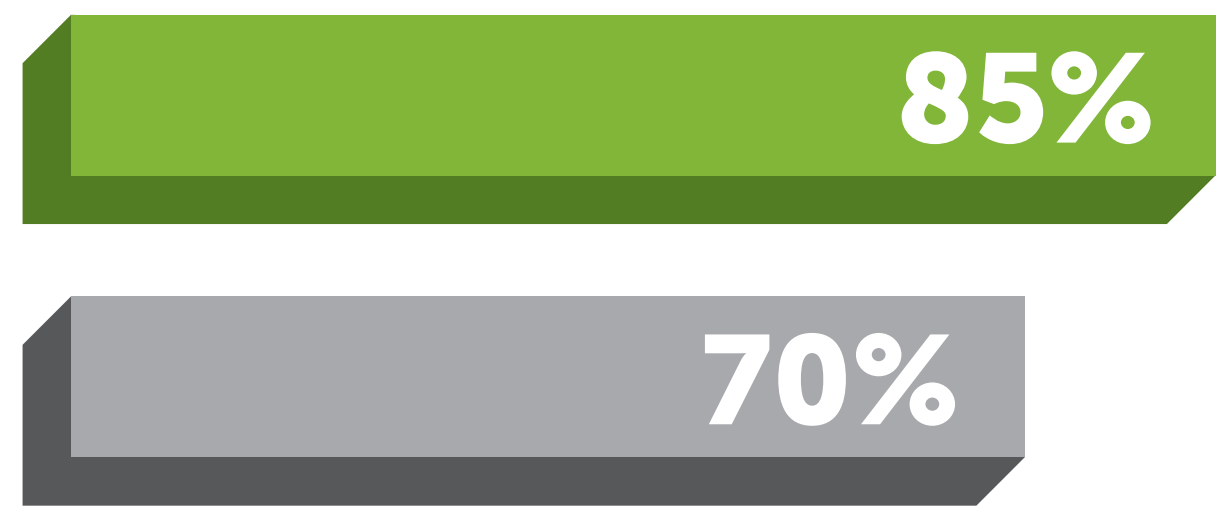

DLP Teachers Non-DLP Teachers 


\section{Teachers who reported more hours of coaching were more likely to see improvement in their professional growth.}

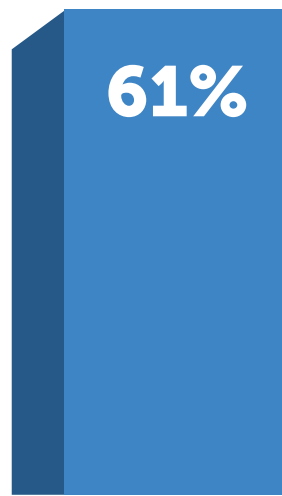

$<6$ hours

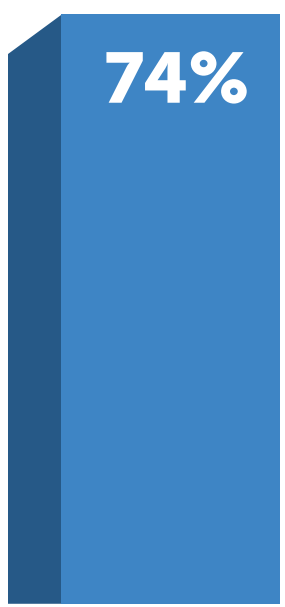

8-12 hours

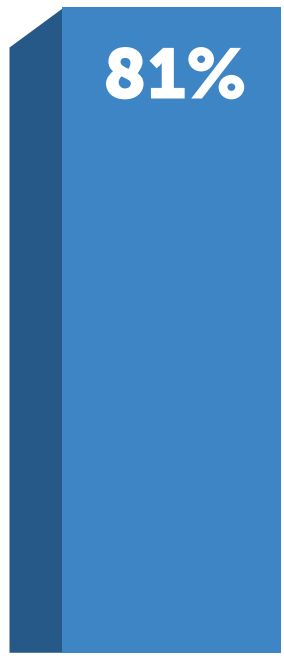

18-24 hours

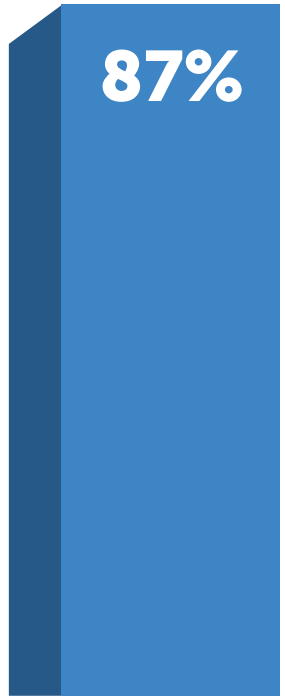

$32+$ hours about, try, and evaluate new ideas, compared to 79 percent of their non-DLP peers. Using knowledge of each teacher's style and attitude, gained through repeated interaction, coaches can anticipate how they will respond to different styles of support and understand how much and in what ways to push them.

Change is a process, rather than an event. When coaches continue to check in and offer support even after a formal coaching cycle has concluded, teachers are more likely to maintain and internalize the progress that they initially made during their coaching cycle.

\section{Content Flexibility}

DLP coaches work with teachers in using technology to support the content being taught. However, it may be more important for coaches to establish a collaborative relationship and encourage perseverance and reflection than it is for coaches to be
How much time did DLP teachers spend with their coaches?

During their participation in eight-week coaching cycles, 86 percent of coached teachers received at least 30 minutes of one-on-one coaching per week, with 42 percent of them receiving more than an hour of coaching each week. Coached teachers received, on average, more than 16 hours of coaching support over the course of the school year. experts in each subject area. At least 85 percent of coaches felt capable and did not find it a challenge to coach outside their own area of subject expertise. And 93 percent of teachers agreed that coaches had the knowledge they needed to help them leverage technology to teach their content areas.

Over the course of the year, coaches experienced significant growth in their knowledge of how teachers can most effectively use technology for teaching content matter. Nearly three quarters (73 percent) of coaches reported being extremely or very comfortable in helping teachers select and use technology to support their content matter, up from 55 percent at the start of the year. Coaches also grew in their knowledge of using technology to improve teachers' pedagogy; by the end of the year, 87 percent of coaches were very comfortable helping teachers improve pedagogy through technology.

Even skeptical teachers found that coaches 
could be content flexible. One middle school art teacher reflected, "Often technology coaches do not consider fine arts when thinking of professional development that is relevant. Our DLP coach was phenomenal at working with me, finding relevant technology to use in the classroom, and taking the time to come to my classroom to work with the students and me during this process. I would recommend that everyone take part in this coaching!"

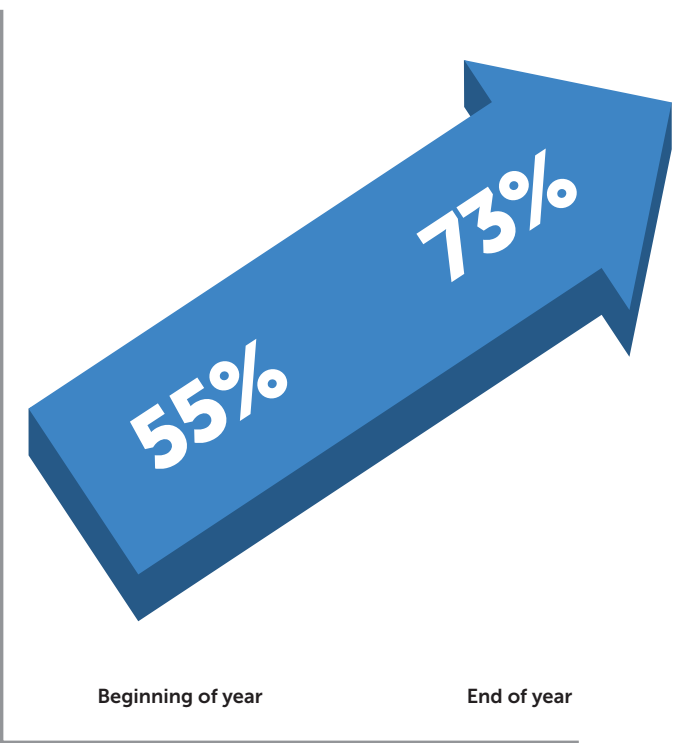

73 percent of coaches reported being extremely or very comfortable in helping teachers select and use technology to support their content matter, up from 55 percent at the start of the year.
Coaches were generally able to help teachers regardless of content area or grade level because they viewed the teacher as the content expert. In fact, some coaches find that a mismatch in content expertise between teacher and coach can be a strength since it lends an outside perspective and an opportunity to consider different resources and approaches. As one coach described, "I think sometimes a viewpoint from someone not familiar with a topic can help teachers avoid assumptions or identify areas where students may also have misconceptions or issues."

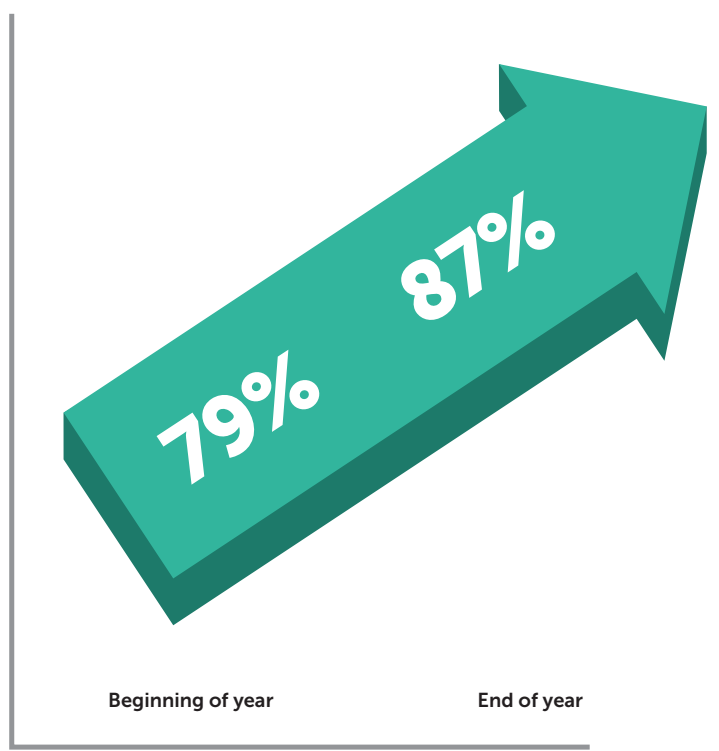

87 percent of coaches reported being extremely or very comfortable in helping teachers improve pedagogy through technology, up from 79 percent at the start of the year. 


\section{Takeaways}

Based on evidence from the DLP, our research suggests the following recommendations for coaches and school leaders in order to implement effective classroom coaching programs:

\section{School and district leaders should work with their coach to:}

\section{- Build Better Partnerships}

- Promote teacher buy-in and direction setting.

- Create a coaching program that is responsive to each school.

- Facilitate the voluntary participation of teachers.

- Let teachers set their own goals for their coaching.

- Protect coaching time.

- Review progress and challenges with regular formal and informal meetings.

- Keep coaching separate from a teacher's formal evaluation.

- Respect coach-teacher confidentiality.

\section{- Promote Teachers' Active Learning}

- Provide frequent and varied opportunities during the school day for teacher sense-making and learning from their collaboration with the coach.

\section{- Personalize Support for Teachers}

- Communicate that coaching is integral to the campus culture and district goals and connected to other initiatives in an organic way.

\section{- Ensure Sustained Support for Professional Growth}

- Grant teachers time and space to engage with, practice, and reflect on new ideas.

- Ensure the coach has time in their schedule to provide sustained follow-up support and informal support to teachers.

\section{- Provide Subject-Specific Support for Teachers and Coaches}

- Create a collaborative environment that allows the teacher to remain the content expert while the coach advises on strategies and tools.

- Help the coach grow in their ability to support all content areas by harnessing mentor and PLN support. 


\section{Conclusion}

The quality and depth of professional development through coaching is what sets DLP apart from other programs. The second year of the Dynamic Learning Project saw almost 2,000 teachers across seven states and all grade levels grow in their impactful use of technology. Coaches increased their ability to connect teachers with technological tools and support innovation in the classroom. As one middle school special education teacher said, "Every school needs

to have a coaching position. It has been wonderful to have someone to help come up with creative teaching ideas and new ways to present information."

As we move into the third year of the Dynamic Learning Project, we will continue to investigate how partnership, active learning, personalization, sustained support, and content flexibility act as the cornerstones of coaching programs. We will also begin to analyze student outcome data from years one and two in order to link changes in teacher use of technology to student achievement.

Administrator and teacher eagerness to continue participating in the program is a testament to the success of the DLP. Teachers explained how the DLP coach's role filled a need on their campus, and even teachers who admitted they had underutilized their coach wanted their coach to remain in their positions. Nearly three quarters (71 percent) of both DLP and non-DLP teachers in participating schools agreed that they would recommend the DLP to other teachers in their schools or in other schools-a number that increases to 86 percent for DLP teachers.

"Administrators have taken their time with the urgent matters of schoolwide discipline and administration of programs and cannot dedicate themselves sufficiently to instructional professional growth as well," said a middle school foreign language teacher. "Teachers' days are long and stressful even without adding in the time and energy needed to research current practices, although some still do. The coach is the bridge to effective practices in research and the introduction and adoption of those practices in the classroom, and the coach can provide the needed consistent follow-up to ensure that effective strategies are implemented."

The flexibility of the DLP and the emphasis on the partnership between teachers, coaches, principals, and district administrators has allowed the DLP to expand with positive results into more schools and more grade levels. "[DLP] coaches are what keep staff members current, relevant, and in touch with the resources available, which then allows them to turn around and engage their students meaningfully without becoming stagnant in their teaching practices," explained one high school English/language arts teacher.

We launched the DLP to address inequities in technology use and to improve teacher effectiveness and student engagement and learning. We are meeting these goals and developing a replicable program that positions coaches to provide the kind of deep support that allows teachers to take risks and flourish. The increase in impactful use of technology catalyzed teacher professional growth as well as student engagement and learning across DLP schools.

There are more than 3.1 million public school teachers across the United States. ${ }^{6}$ Every one of them deserves the kind of support, resources, and partnership that the Dynamic Learning Project provides. Our goal is that more schools will implement high-quality and effective coaching programs like the Dynamic Learning Project so that teachers can improve their impactful use of technology and be better able to provide students with an excellent, engaging, and equitable education. 